\title{
Electrodeposited Platinum Iridium Enables Microstimulation With Carbon Fiber Electrodes
}

\author{
Elena della Valle ${ }^{1,2 *}$, Beomseo Koo ${ }^{1,2}$, Paras R. Patel ${ }^{1,2}$, Quentin Whitsitt ${ }^{3}$, Erin K. Purcell ${ }^{3}$, \\ Cynthia A. Chestek ${ }^{1,2,4,5,6}$ and James $D$. Weiland ${ }^{1,7,2}$
}

\begin{abstract}
${ }^{1}$ Biomedical Engineering Department, University of Michigan, Ann Arbor, MI, United States, ${ }^{2}$ Biointerfaces Institute, University of Michigan, Ann Arbor, MI, United States, ${ }^{3}$ College of Engineering, Michigan State University, East Lansing, IN, United States, ${ }^{4}$ Department of Electrical Engineering and Computer Science, University of Michigan, Ann Arbor, MI, United States, ${ }^{5}$ Robotics Graduate Program, University of Michigan, Ann Arbor, MI, United States, ${ }^{6}$ Neuroscience Graduate Program, University of Michigan, Ann Arbor, MI, United States, ${ }^{7}$ Department of Ophthalmology and Visual Sciences, Kellogg Eye Center, University of Michigan, Ann Arbor, MI, United States
\end{abstract}

OPEN ACCESS

Edited by: Hui Fang,

Dartmouth College, United States

Reviewed by:

Hyowon Lee,

Purdue University, United States

Wonryung Lee,

Korea Institute of Science and Technology, South Korea Yongli Qi,

Dartmouth College, United States

${ }^{*}$ Correspondence:

Elena della Valle

eldellav@umich.edu

Specialty section: This article was submitted to Nanodevices,

a section of the journal

Frontiers in Nanotechnology

Received: 24 September 2021 Accepted: 10 November 2021

Published: 02 December 2021

Citation:

della Valle $E, K o o B$, Patel $P R$, Whitsitt Q, Purcell EK, Chestek CA and Weiland JD (2021) Electrodeposited

Platinum Iridium Enables Microstimulation With Carbon Fiber Electrodes.

Front. Nanotechnol. 3:782883. doi: 10.3389/fnano.2021.782883
Ultrasmall microelectrode arrays have the potential to improve the spatial resolution of microstimulation. Carbon fiber (CF) microelectrodes with cross-sections of less than $8 \mu \mathrm{m}$ have been demonstrated to penetrate cortical tissue and evoke minimal scarring in chronic implant tests. In this study, we investigate the stability and performance of neural stimulation electrodes comprised of electrodeposited platinum-iridium (PtIr) on carbon fibers. We conducted pulse testing and characterized charge injection in vitro and recorded voltage transients in vitro and in vivo. Standard electrochemical measurements (impedance spectroscopy and cyclic voltammetry) and visual inspection (scanning electron microscopy) were used to assess changes due to pulsing. Similar to other studies, the application of pulses caused a decrease in impedance and a reduction in voltage transients, but analysis of the impedance data suggests that these changes are due to surface modification and not permanent changes to the electrode. Comparison of scanning electron microscope images before and after pulse testing confirmed electrode stability.

Keywords: carbon fiber microelectrode (CFME), PtIr coating, microstimulation, in vivo stimulation, in vitro stimulation

\section{INTRODUCTION}

Ultramicroelectrodes are a class of neural interfaces distinguished by cross-sectional dimensions of less than 15 microns. Ultramicroelectrodes include carbon fiber arrays (Patel et al., 2015; Welle et al., 2020), the Neurolace and NET probes (Xie et al., 2015), silicon carbide microelectrodes (SiC) (Deku et al., 2018), high density microwires (Kollo et al., 2020), and 3D printed arrays (Ali et al., 2021). These devices drastically reduce the foreign body reaction compared to penetrating arrays with larger features (Polikov et al., 2005). The small size of ultramicroelectrodes makes them challenging to utilize since they either lack the stiffness to penetrate the brain (and require a temporary stiffener) or are brittle and thus difficult to handle. Polyimide is an example of an electrode substrate that requires a stiffener while silicon is an example of an electrode that is stiff but brittle at dimensions below 15 microns. Carbon fiber (CF) ultramicroelectrodes have proven to be strong enough to penetrate the cortex (Patel et al., 2015; Patel et al., 2016; Massey et al., 2019) and peripheral nerve (Gillis et al., 2018; Dehdashtian et al., 2020) yet small enough to evoke minimal foreign body reaction (Deku et al., 2018; 
Kozai et al., 2012; Patel et al., 2016; Welle et al., 2020, 2021). Since carbon is also conductive, it can serve as both a mechanical substrate and electrical conductor for an ultramicroelectrode (Kozai et al., 2012; Patel et al., 2016; Jiman et al., 2020). However, carbon is not efficient for neural stimulation. This limitation, along with the small dimensions of ultramicroelectrodes, requires enhancement of carbon by coating with an additional material suitable for neural stimulation.

Platinum and platinum-iridium are widely used for neural stimulation (Cogan, 2008). Due to their proven efficiency and stability, these materials are used in clinical devices such as deep brain stimulators, which use macroelectrodes (millimeter dimensions), and therefore can stay within charge density limits $\left(30 \mu \mathrm{C} / \mathrm{cm}^{2}\right.$ (Cogan et al., 2016)), and still provide therapeutic levels of stimulation. However, the smaller electrodes site sizes used by ultramicroelectrodes may require a charge density above this limit to evoke responses from cortical cells. Motivated by this need, several alternative materials with improved charge injection capability have been developed. Porous titanium nitride (TiN) has shown biocompatibility and stability along with large charge-injection capacities due to surface roughness. However, accessing the full charge storage capacity under the high current density of neural stimulation is limited by the pore resistance (Posey and Morozumi, 1966; Goldberg et al., 1972; Norlin et al., 2004). The porous platinum known as "Pt gray" can inject a charge density of $1.4 \mathrm{mC} / \mathrm{cm}^{2}$ (Zhou, 2005; Zhou, 2011; Fan et al., 2020) without causing material damage or irreversible reactions. Nanostructered platinum (nanoPt) has been recently investigated (Boehler et al., 2020; Wang et al., 2021) through in vitro and in vivo testing as a potential electrochemical coating both for neural recording and stimulation. Reproducibility of the coating process and stimulation performance for small microelectrodes (cross-section $<100 \mu \mathrm{m}$ ) has not been evaluated yet. Hydrated Ir oxide films as activated or sputtered iridium oxide (AIROF or SIROF respectively) have reported high charge injection capabilities (Beebe and Rose, 1988; Klein et al., 1989) in the range of $1-5 \mathrm{mC} / \mathrm{cm}^{2}$. Further, poly (3,4-ethylenedioxythiophene) polystyrene sulfonate (PEDOT-PSS) has shown a charge injection capacity three times higher than AIROF or SIROF (Cogan et al., 2007) although PEDOT stability and robustness remain questionable (Dupont et al., 2014; Welle et al., 2020). Electrodeposited platinum iridium (PtIr) has demonstrated reduced impedance (Cassar et al., 2019; Welle et al., 2020; Della Valle et al., 2021) and lower voltage transients during pulsed current stimulation (Lee et al., 2018), compared to uncoated control electrodes. A recent study (Dalrymple et al., 2019) made a direct comparison between electrodeposited PtIr, reduced graphene oxide, and conducting hydrogel electrodes, finding that PtIr retained low impedance after pulse testing, while graphene failed and conducting hydrogel impedance trended higher. In our previous work (Della Valle et al., 2021) we analyzed the coating morphology of PtIr coated CFs and demonstrated a good coating adhesion during accelerated soak testing.
Here we evaluate CF microelectrode arrays coated with electrodeposited PtIr (PtIr-CF) under conditions of in vitro pulse testing at rates of $300 \mathrm{~Hz}$ (Chen et al., 2020) and $10 \mathrm{kHz}$ (Kapural et al., 2015), which are of interest in neural engineering, specifically for visual cortex stimulation and high frequency spinal cord stimulation respectively. We characterized PtIr-CF electrodes with electrochemical impedance spectroscopy (EIS), cyclic voltammetry (CV), voltage transients (VT), and scanning electron microscopy (SEM) before and after the coating as well as before and after in vitro pulsing tests. Voltage transients were stable during the pulsing process and no delamination was apparent in pulsed electrodes. We also report data from two pilot studies: in vitro pulse testing of cellular scale PtIr-CF electrode and in vivo pulsing conducted in the visual cortex of a single animal.

\section{MATERIALS AND METHODS}

\subsection{Carbon Fibers Microelectrode Arrays Fabrication}

The carbon fiber electrode arrays (CFEA) consist of eight sharpened CFs coated with a Parylene C insulation layer $(800 \mathrm{~nm})$ and are attached to a small printed circuit board [ZIF Probe, ZIF, (Patel et al., 2016)]. Insulation is removed at the tip using a blowtorching process (Welle et al., 2021) to expose $100-150 \mu \mathrm{m}$ of carbon with sharpened tips. The final tip diameter tapers from 8.4 to $\sim 2 \mu \mathrm{m}$ diameter at the tip.

One ZIF with $8 \mathrm{CFs}$ with a small tip exposure was used for the pilot study of in vitro pulsing tests of cellular scale PtIr-CF. For the tip preparation of these CFs, instead of the blowtorching method, a scissor was used to expose the CF at the tip. Once cut, the CFs were coated with PtIr (area of $\sim 108 \mu \mathrm{m}^{2}$, see inset of Figure 7A).

For in vivo pulsing tests, one high density carbon fiber (HDCF) array was used. The HDCF fabrication is described elsewhere (Huan et al., 2021). Briefly, the array consisted of 16 silicon shanks of $6 \mathrm{~mm}$ length with approximately $250 \mu \mathrm{m}$ of $\mathrm{CF}$ protruding from the end of each shank. Parylene-C was used as an insulation layer and the CF tips were blowtorched to expose and sharpen the CF tips, exposing $\sim 100-150 \mu \mathrm{m}$.

\subsection{Electrochemical Impedance Spectroscopy and Cyclic Voltammetry}

EIS was collected by applying a $10 \mathrm{mV}$ (peak) sine wave in a frequency range of $1 \mathrm{MHz}-10 \mathrm{~Hz}$. All EIS and CV measurements were performed in $1 \mathrm{x}$ PBS ( $0.01 \mathrm{M}$ phosphate buffered saline) solution in a three electrode configuration at open circuit potential using a PtIr wire electrode $(\sim 70 \mu \mathrm{m})$ as counter and an $\mathrm{Ag} / \mathrm{AgCl}$ as reference electrode $(3 \mathrm{M} \mathrm{NaCl}$, BASi, West Lafayette, IN, United States). A Gamry 600+ potentiostat (Gamry Inc., Warminster, PA, United States) was used for measurement collection.

Cyclic voltammetry $(\mathrm{CV})$ measurements were obtained by sweeping three times between -0.6 and $0.8 \mathrm{~V}$ versus $\mathrm{Ag} / \mathrm{AgCl}$ at a scan rate of $500 \mathrm{mV} / \mathrm{s}$. CVs were measured to establish the 


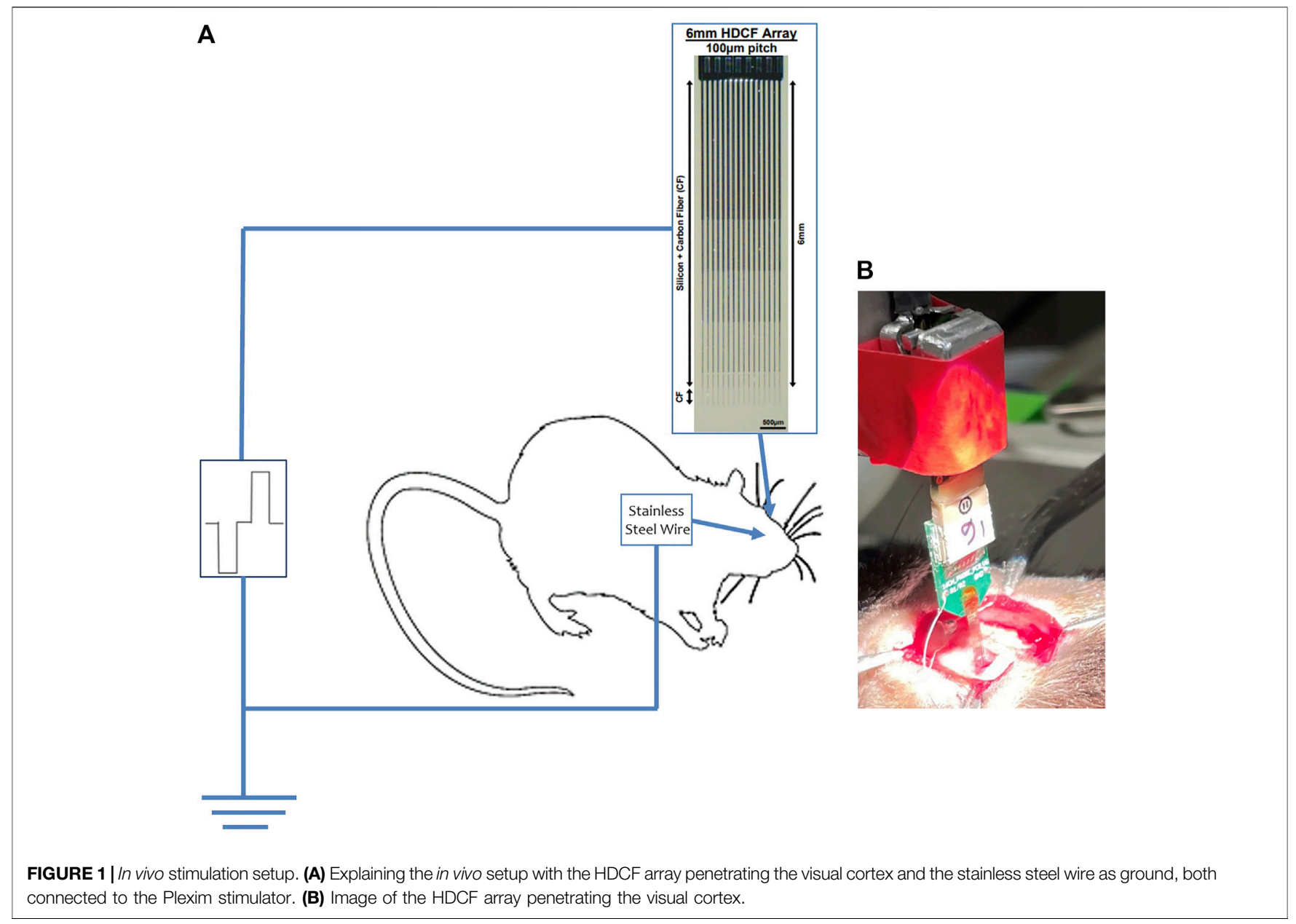

cathodal charge storage capacity $\left(\operatorname{CSC}_{C}\right)(\operatorname{Cogan}, 2008)$. We calculated $\mathrm{CSC}_{C}$ from the time integral of the cathodic current.

\subsection{Pt-Ir Electrochemical Deposition}

PtIr coatings were electrodeposited using a potential cycling technique in a solution of $0.2 \mathrm{~g} / \mathrm{L}$ of $\mathrm{Na}_{3} \mathrm{IrCl}_{6} \mathrm{H}_{2} \mathrm{O}$ and $0.186 \mathrm{~g} /$ $\mathrm{L}$ of $\mathrm{Na}_{2} \mathrm{PtCl}_{6} \mathrm{H}_{2} \mathrm{O}$ in $0.1 \mathrm{M}$ of nitric acid $\left(\mathrm{HNO}_{3}\right.$ ) (Della Valle et al., 2021). A constant temperature of $56^{\circ} \mathrm{C}$ and a pulsed sonication at a power of $2 \mathrm{~W}\left(\mathrm{~T}_{O N}=1 \mathrm{~min}\right.$ and $\mathrm{T}_{O F F}=$ $30 \mathrm{sec}$.) were used. A $70 \mu \mathrm{m}$ PtIr wire (A-M System, Sequim, WA, United States) electrode and an $\mathrm{Ag} / \mathrm{AgCl}(3 \mathrm{M} \mathrm{NaCl}, \mathrm{BASi}$, West Lafayette, IN, United States) were used as counter and reference electrode respectively. The potential range for the electrodeposition process was -0.1 to $0.1 \mathrm{~V}$ with $200 \mathrm{mV} / \mathrm{s}$ of scan rate for 1,200 cycles, which corresponds to a coating process time of $45 \mathrm{~min}$. A Gamry 600+ potentiostat (Gamry Instruments, Warminster, PA, United States) was used to apply potential cycles and an A700 Qsonica (Qsonica L.L.C. Newtown, CT, United States) was used for sonication.

\subsection{SEM Images Acquisition}

Images of CFs were acquired with scanning electron microscopy (SEM) before coating, after coating, and after pulse testing, using a Tescan Rise SEM (Tescan Orsay Holding, Brno-Kohoutovice, Czech Republic) in low vacuum mode (LVSTD, low vacuum secondary electron Tescan detector). Low vacuum mode allows imaging without deposition of a conductive film (i.e., gold). Samples were mounted on SEM stubs with the conductive carbon tape without the CF touching the tape. An excitation voltage between 5 and $20 \mathrm{kV}$ was used.

\subsection{In-vitro Pulse Testing}

\subsection{1 $300 \mathrm{~Hz}$ and $10 \mathrm{kHz}$ in Vitro Pulsing Test}

A PlexStim Electrical Stimulator System (Plexon, Dallas, TX, United States, software version 2.3) was used to deliver cathodic first biphasic electric pulses with a charge density of $1 \mathrm{mC} / \mathrm{cm}^{2}$. A bipolar stimulation was done choosing as ground one PtIr-CF on the pulsed CFEA. Two different current amplitude and pulse duration were applied on the sharp carbon fibers:

1) Electric pulses with a duration of $170 \mu \mathrm{s}$, interphase of $60 \mu \mathrm{s}$ at a frequency of $300 \mathrm{~Hz}$. Pulsing tests were conducted for $12 \mathrm{~h}$ ( $\sim 13$ million pulses);

2) Electric pulses with $30 \mu$ s of duration at a frequency of $10 \mathrm{kHz}$ for $3 \mathrm{~h}$ ( 108 million pulses). 

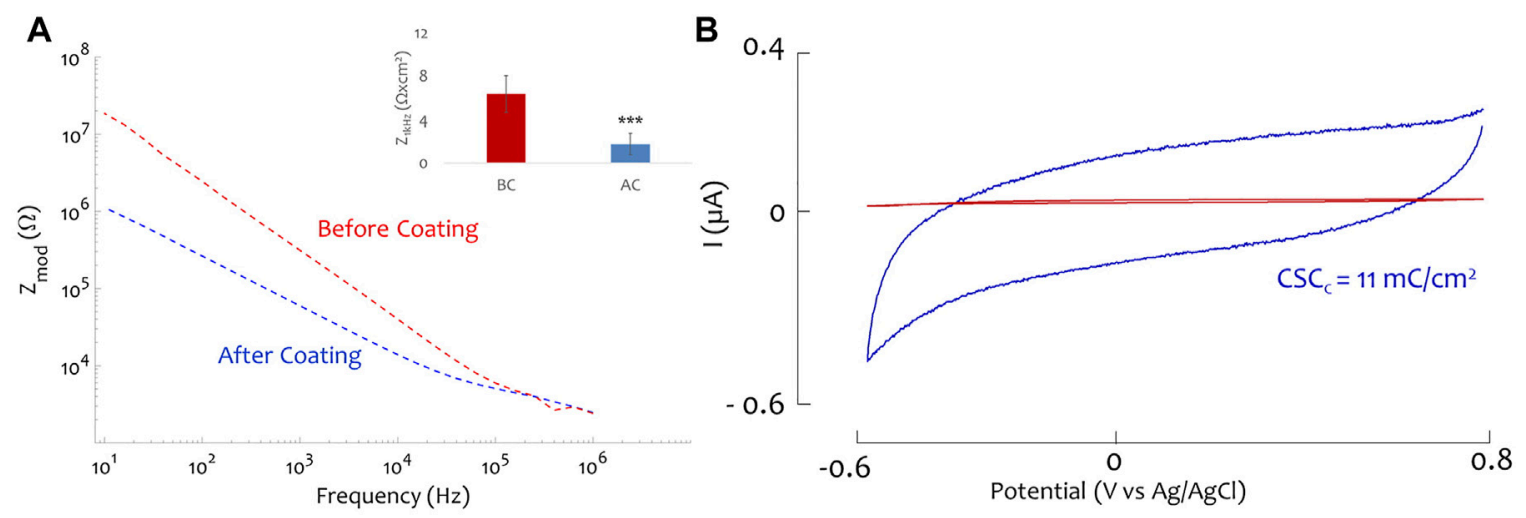

FIGURE 2 | PtIr coated carbon fiber. (A) Electrochemical impedance spectroscopy (EIS) measurement of one sharpened carbon fiber before and after the plating process; as inset the mean and standard deviation of the normalized impedance is reported before (red) and after (blue) the coating, ${ }^{\star \star \star}$ indicate a $p$-value $=1.02 \times 10^{-18}$. (B) Cyclic voltammetry (CV) of a sharpened carbon fiber before (red) and after (blue) the Ptlr plating process, the cathodic charge storage capacity of the electrode increases to $11 \mathrm{mC} / \mathrm{cm}^{2}$ after the coating $\left(0.2 \mathrm{mC} / \mathrm{cm}^{2}\right.$ before the coating).

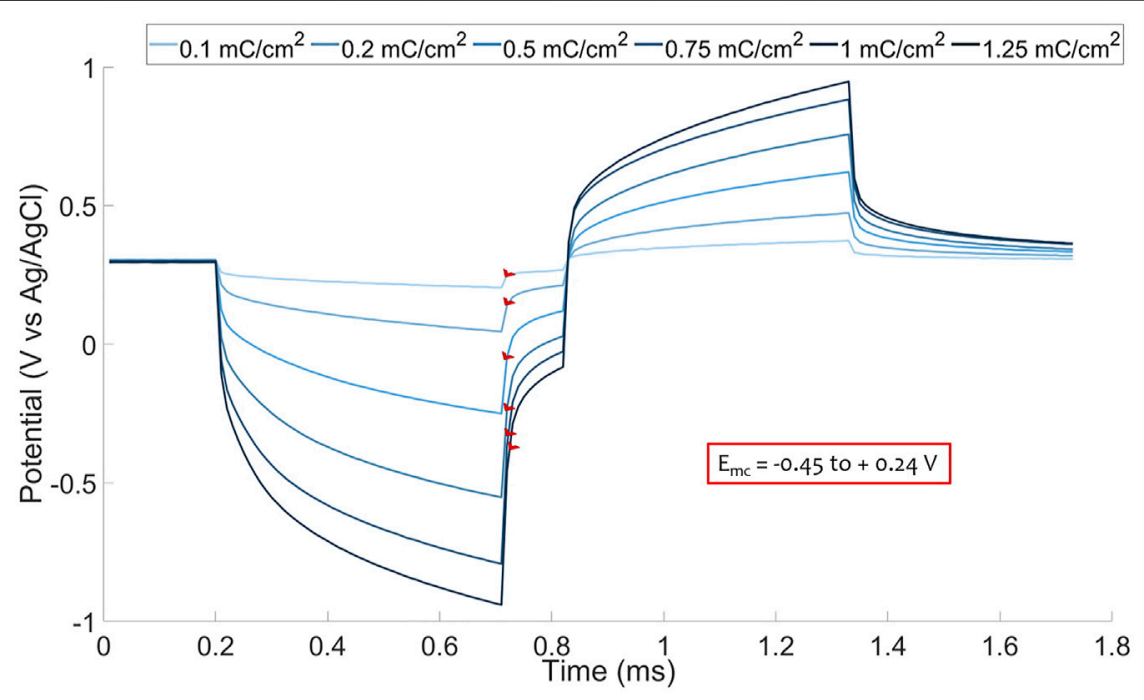

FIGURE 3 | $\mathrm{E}_{m c}$ Characterization. Voltage transients of one Ptlr-CF vs the Ag/AgCl reference electrode for charge density from 0.1 to $1.25 \mathrm{mC} / \mathrm{cm}^{2}$. The $\mathrm{E}_{m c}$ ranges from -0.45 to $0.24 \mathrm{~V}$ in the range of the water electrolysis window for Ptlr coatings (-0.6 to 0.8 V) (Rose and Robblee, 1990$)$.

EIS measurements were taken before and after electric pulsing tests. All the experiments were conducted at room temperature. SEM images were collected before and at the end of pulsing tests to determine surface modifications due to the electric stimulation. The PlexStim provides single ended outputs of the current waveform (presented as a voltage across a resistor) and the VT across the test and counter electrodes. The current and the VT were monitored both for in vitro and in vivo pulsing tests, using a digital oscilloscope (Tektronix TBS 1032B, Beaverton, OR, United States). The electrochemical cell used consisted of a petri dish (Millipore Sigma, diameter of $80 \mathrm{~mm}$ and a volume of $\sim 75 \mathrm{ml}$ ) containing $1 \mathrm{x}$ of a PBS solution; the leads of the stimulator were connected to the pulsed carbon fiber, and the ground connected to one of the CFs of the pulsed ZIF board.

\subsubsection{Electrode Polarization}

A three electrode configuration method was used to measure the maximum cathodic polarization, $\mathrm{E}_{m c}$ of PtIr-CF electrode (Cogan, 2008). For that purpose, we used the chronoamperometry experiment of the Gamry potentiostat. An $\mathrm{Ag} / \mathrm{AgCl}$ and a large $\mathrm{Pt}$ foil $\left(5 \times 9 \mathrm{~mm}^{2}\right)$ were used as reference and counter electrodes respectively. Biphasic cathodic first current pulses of duration of $500 \mu$ s and charge intensity from 0.1 to $1.25 \mathrm{mC} / \mathrm{cm}^{2}$ were applied.

\subsubsection{In vitro Cellular Scale PtIr-CF Pulsing Test}

One ZIF board with eight small PtIr-CFs (section 2.1 for fabrication details) was characterized by means of pulsing tests. A PlexStim Electrical Stimulator System (Plexon, Dallas, TX, United States, software version 2.3) was used to deliver 

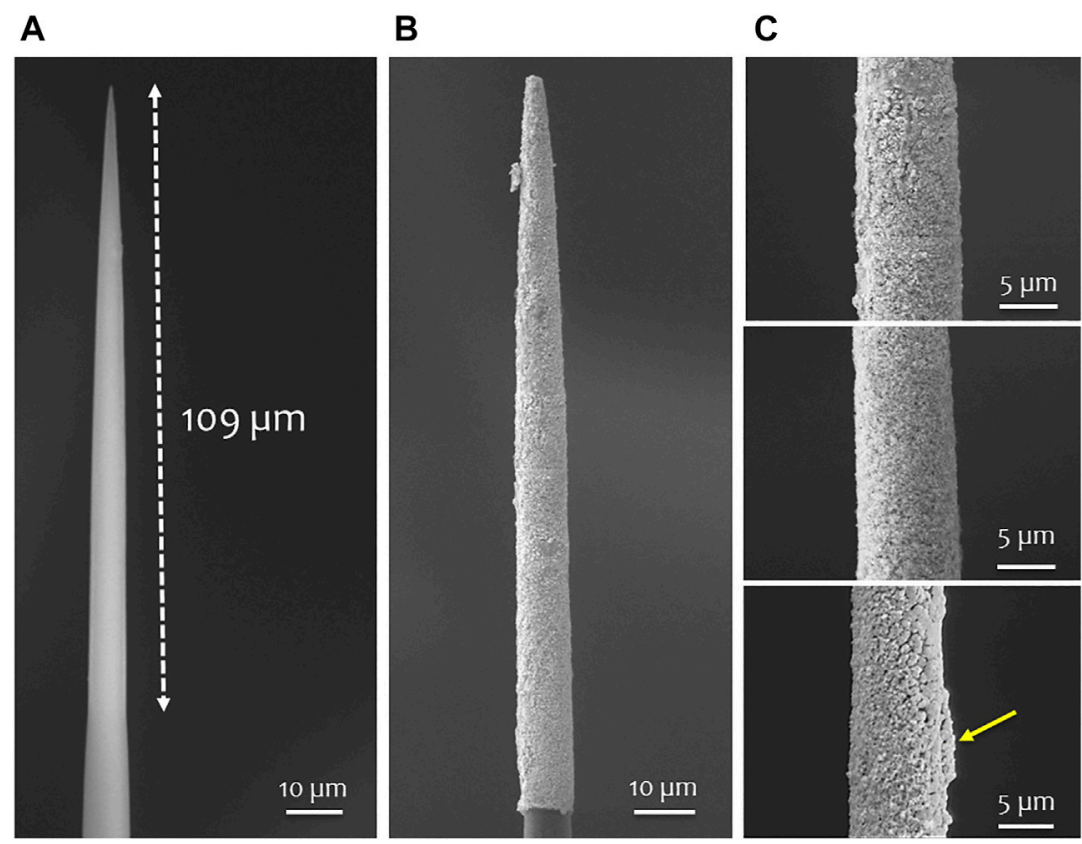

FIGURE 4 | SEM of PtIr-CF. SEM of a carbon fiber with an exposed surface of $109 \mu \mathrm{m}$ before (A) and after the PtIr coating (B); (C) SEM images of three different PtIr-CF.

TABLE 1 | Mean and standard deviation of the normalized impedance at $1 \mathrm{kHz}$, list of all components extracted from the equivalent circuit model (see inset of Figure $\mathbf{5 A}$ ), $\mathrm{VT}_{\text {peak }}$ for Day 1 and Day 2 before and after pulsing. The $p$-value from the paired t-test are reported with a significance difference for the constant phase element components as well as for normalized impedance at $1 \mathrm{kHz}$ and the $\mathrm{VT}_{\text {peak }}$ before and after pulsing on Day 1 and Day 2.

\begin{tabular}{|c|c|c|c|c|c|c|}
\hline & $\left.\mathrm{Z}_{1 \mathrm{kHz}} \Omega \mathrm{xcm}^{2}\right)$ & $\mathrm{Ru}(\Omega)$ & YO $\left(\mathbf{S}^{\star} \mathbf{S}^{\alpha}\right)$ & $\alpha$ & C (F) & $\mathbf{V T}_{\text {peak }}$ \\
\hline $\mathrm{BP}_{\text {Day } 1}$ & $0.69 \pm 0.1$ & $6.8 \pm 2.1 \times 10^{3}$ & $2.13 \pm 0.86 \times 10^{-7}$ & $0.58 \pm 0.05$ & $5.01 \pm 0.94 \times 10^{-11}$ & $1.19 \pm 0.08$ \\
\hline $\mathrm{AP}_{\text {Day } 1}$ & $0.27 \pm 0.02$ & $6.2 \pm 0.74 \times 10^{3}$ & $2.9 \pm 1.1 \times 10^{-7}$ & $0.7 \pm 0.05$ & $5.48 \pm 0.68 \times 10^{-11}$ & $0.94 \pm 0.1$ \\
\hline$p$-value Day $1_{1}$ & $7.45 \times 10^{-5}$ & 0.33 & 0.003 & $1.29 \times 10^{-5}$ & 0.25 & $9 \times 10^{-7}$ \\
\hline $\mathrm{BP}_{\text {Day } 2}$ & $0.6 \pm 0.13$ & $6.7 \pm 1.5 \times 10^{3}$ & $2.7 \pm 0.8 \times 10^{-7}$ & $0.49 \pm 0.05$ & $5.45 \pm 1 \times 10^{-11}$ & $1.1 \pm 0.11$ \\
\hline $\mathrm{AP}_{\text {Day2 }}$ & $0.25 \pm 0.04$ & $6 \pm 1.1 \times 10^{3}$ & $3.63 \pm 1.2 \times 10^{-7}$ & $0.7 \pm 0.05$ & $5.4 \pm 1.7 \times 10^{-11}$ & $0.93 \pm 0.1$ \\
\hline$p$-value ${ }_{\text {Day2 }}$ & $6.41 \times 10^{-6}$ & 0.07 & 0.0026 & $2.15 \times 10^{-5}$ & 0.97 & 0.0014 \\
\hline
\end{tabular}

cathodic first biphasic electric pulses with a duration and interphase gap of $100 \mu \mathrm{s}$ at $100 \mathrm{~Hz}$. Current amplitudes ranged from 5 to $20 \mu \mathrm{A}$. The pulse was applied for the duration of $1 \mathrm{~min}$ per CF. A $70 \mu \mathrm{m}$ PtIr wire was used as the counter electrode.

\subsection{In vivo Pulsing Tests}

\subsubsection{High Density Carbon Fiber Array Fabrication}

One HDCF (section 2.1 for details) array was used for in vivo visual cortex stimulation. The HDCF used for this experiment consisted of four CF electrodes, one coated CF for pulse testing and three for stab controls, with the remaining 12 fibers removed for easier insertion.

\subsubsection{Rat Surgery}

The surgical procedure used was approved by the Michigan State University Animal Care and Use Committee. One SpragueDawley rat was anesthetized with $3 \%$ isoflurane and maintained at $1-3 \%$. Once hind-limb pinch response was muted, the rat's head was shaven and placed on a stereotaxic with an anesthesia nosecone, and the head was fixed with ear bars. A longitudinal incision was made at the dorsal surface of the animal's head, the fascia was removed, and the exposed skull was cleaned and dried. Excessive bleeding of the skull or surrounding skin was stopped with either absorbent spear or cauterization. A $3 \times 3 \mathrm{~mm}$ craniotomy at the primary visual cortex (V1) was made using this coordinate: (Anterior-Posterior, Medial-Lateral) (-6.5, -3.5) $\mathrm{mm}$ from Bregma.

\subsubsection{In vivo Stimulation Protocol}

For in vivo stimulation, the dura was removed and the PtIrHDCF was driven into the cortex until a depth of $300 \mu \mathrm{m}$ was reached. An $8 \mathrm{~cm}$ stainless steel wire (A-M Systems) was used as a stimulation return electrode. One minute after insertion, the PtIrHDCF was connected to the Plexon PlexStim system, and the stimulation return electrode was sutured under the loose skin at the incision site using vicryl sutures. Cathodic-first, symmetricbiphasic pulses with $200 \mu$ s duration per phase, $100 \mu$ s interphase gap, and $50 \mathrm{~Hz}$ pulse frequency were used with four amplitudes: 


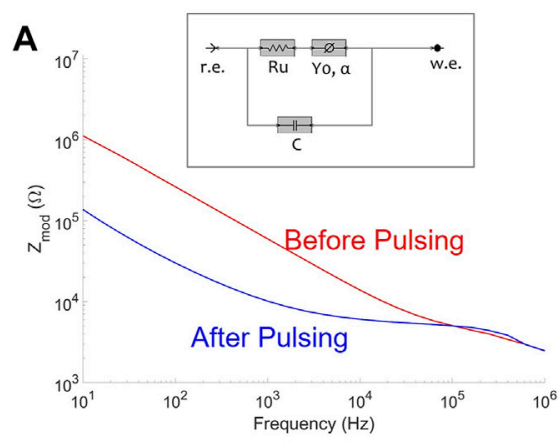

C

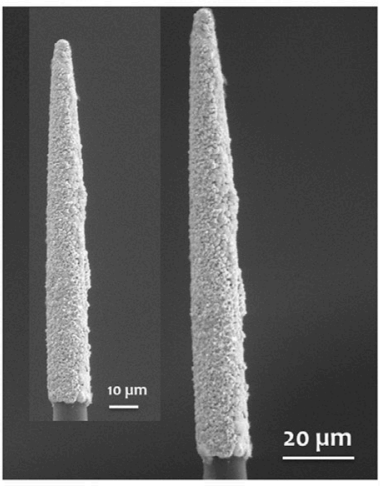

B

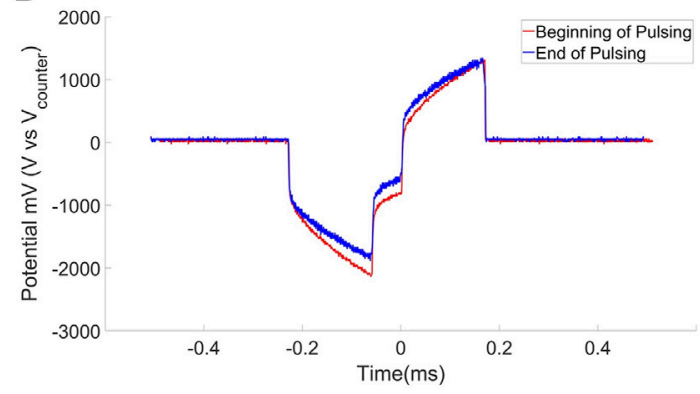

E

FIGURE 5|300 Hz Electric pulse test. (A) EIS of one Ptlr-CF before (red solid line) and after (blue solid line) pulsing on Day1; as inset the circuit model used for fitting impedance data is shown. (B) Voltage transient for one PtIr-CF in the beginning (red) and at the end of pulsing test (blue); a biphasic pulse of $170 \mu \mathrm{s}$ duration and amplitude of $105 \mu \mathrm{A}\left(1 \mathrm{mC} / \mathrm{cm}^{2}\right)$ was applied. (C-E) SEM of three Ptlr-CF before as inset and after $12 \mathrm{~h}$ of pulsing test.

$10,15,20,25 \mu \mathrm{A}$ (from 0.1 to $0.3 \mathrm{mC} / \mathrm{cm}^{2}$ ). 6,000 pulses were applied for each current amplitude. After collection of VT, the electrode was driven further into the tissue until $600 \mu \mathrm{m}$, and the tissue was stimulated for a total of $1 \mathrm{~h}(\sim 180 \mathrm{k}$ pulses $)$ at $25 \mu \mathrm{A}$ $\left(0.3 \mathrm{mC} / \mathrm{cm}^{2}\right)$ and $5 \mu$ interphase gap. VTs were collected every 10 minutes.

The summary image shown in Figure 1A explains the in vivo setup, with the HDCF array penetrating the visual cortex and the stainless steel wire as the counter electrode.

\subsection{Statistical Analysis and Electric Circuit Model}

A paired t-test was used to compare impedance data for $\mathrm{CF}$ and PtIr-CF as well as to compare $\mathrm{CSC}_{C}$ prior to and after the coating. A paired t-test was also applied to impedance data before and after pulsing both at 300 and $10 \mathrm{kHz}$. One paired t-test was done for comparing the $\mathrm{VT}_{\text {peak }}$ of the $\mathrm{VT}$ at the beginning and at the end of each pulse test.

Impedance before and after pulsing at both $300 \mathrm{~Hz}$ and $10 \mathrm{kHz}$ were fitted to a circuit model (see inset of Figure 5A). The circuit model consisted of a reference electrode (r.e.), the electrolyte resistance $(\mathrm{Ru})$, the admittance $(\mathrm{Y} 0)$, and the exponent $(\alpha)$ of the constant phase element (CPE), the parasitic capacitance $(\mathrm{C})$, and the working electrode (w.e.). The extracted parameters were statistically analyzed using a paired t-test. For all the statistical tests, Matlab R2021a was used.

\section{RESULTS}

\subsection{PtIr Coating Protocol Assessment}

A total of 39 blowtorched CFs (distributed across five ZIF Boards) were coated with PtIr. The surface area was estimated by SEM inspection and ranged from 1900 to $3,600 \mu \mathrm{m}^{2}$. The impedance data were normalized by the electrode area $(\Omega \times$ $\mathrm{cm}^{2}$ ). An average $1 \mathrm{kHz}$ normalized impedance and standard deviation of $1.74 \pm 0.98 \Omega \times \mathrm{cm}^{2}$ was measured for PtIr-CF. Figure 2A shows a representative impedance spectrum from before and after PtIr coating and average data at $1 \mathrm{kHz}$, normalized to surface area. A significant decrease ( $p$-value of $1.02 \times 10^{-18}$ ) in $1 \mathrm{kHz}$ impedance is noted, while impedance above $100 \mathrm{kHz}$ state is unchanged, indicating no change in geometric surface area.

In Figure 2B, the cyclic voltammetry $(\mathrm{CV})$ is reported for one $\mathrm{CF}$ prior (red) and after the PtIr coating. From the CV, the $\mathrm{CSC}_{C}$ (Cogan, 2008) can be quantified. In the example reported in Figure $2 \mathbf{B}$ the PtIr enhanced the $\mathrm{CSC}_{C}$ from 0.2 to $11 \mathrm{mC} / \mathrm{cm}^{2}$. $\mathrm{CV}$ was done for $21 \mathrm{CFs}$ and the mean and standard deviation of the $\mathrm{CSC}_{C}$ was of $0.25 \pm 0.13 \mathrm{mC} / \mathrm{cm}^{2}$ and $13.1 \pm 8.74 \mathrm{mC} / \mathrm{cm}^{2}$ for 


\section{A

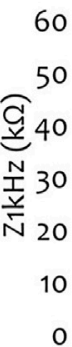

C

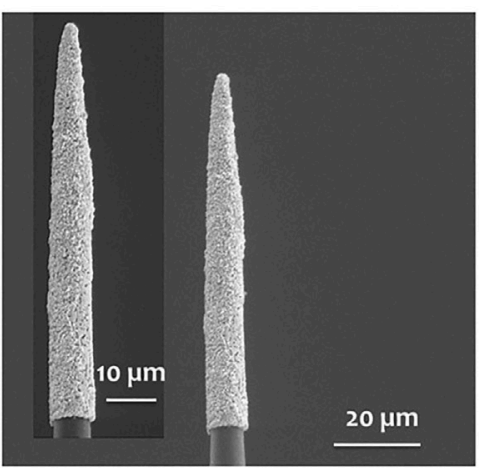

B

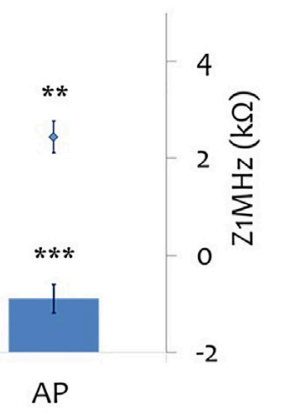

D

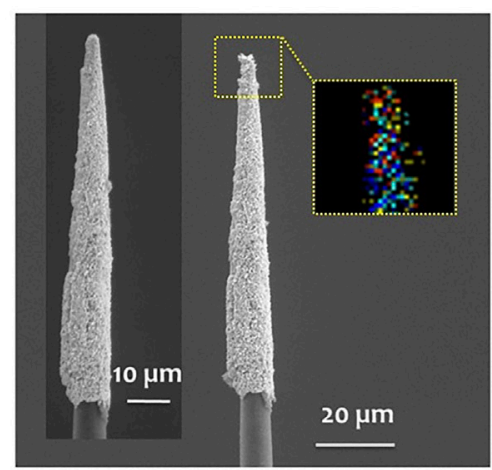

B $\quad$ Beginning of Pulsing

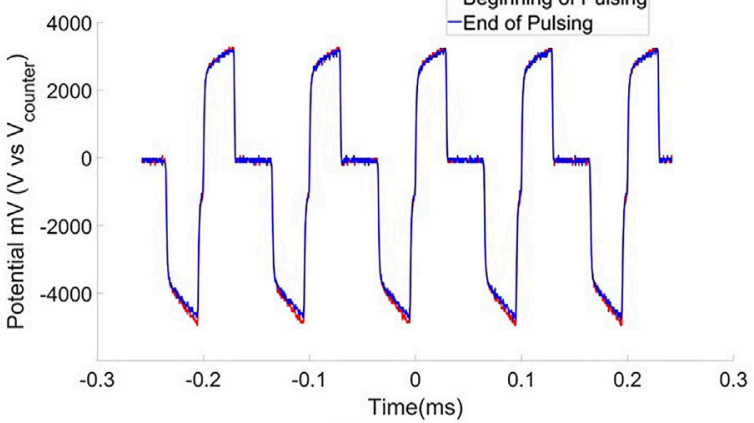

E

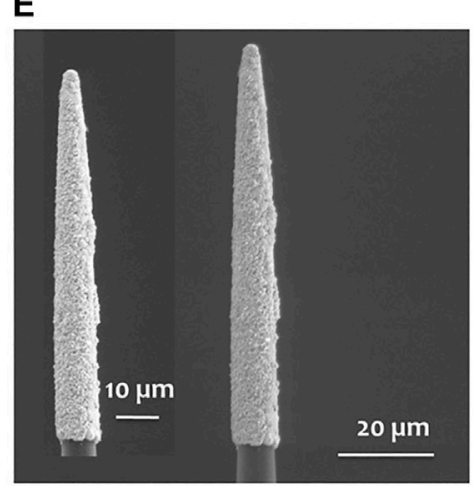

FIGURE 6 | $10 \mathrm{kHz}$ Electric pulse test. (A) EIS of one PtIr-CF before (red solid line) and after (blue solid line) the pulsing test. (B) Voltage transient for one PtIr-CF at the beginning (red) and at the end (blue) of pulsing test; a biphasic pulse of $30 \mu$ s duration and amplitude of $710 \mu \mathrm{A}\left(1 \mathrm{mC} / \mathrm{cm}^{2}\right)$ was applied. (C-E) SEM of three Ptlr-CFs before (as inset) and after $3 \mathrm{~h}$ of electric pulsing, in (D) one EDS is reported as inset with highlighted (yellow box) on the tip the presence of $\mathrm{Na}$ (red) and $\mathrm{Cl}$ (yellow) molecules, in blue and cyan the Ir and Pt molecules are shown as well.

TABLE 2 | Mean and standard deviation of the normalized impedance at $1 \mathrm{kHz}$, list of all components extracted from the equivalent circuit model reported as inset in Figure 5A, $\mathrm{VT}_{\text {peak }}$ before and after pulsing. The $p$-values from the paired t-test are reported with a significance difference for the $\alpha$ value of the CPE and for both normalized impedance and $\mathrm{VT}_{\text {peak. }}$.

\begin{tabular}{|c|c|c|c|c|c|c|}
\hline & $\left.\mathrm{Z}_{1 \mathrm{kHz}} \Omega \mathrm{xcm}^{2}\right)$ & $\mathrm{Ru}(\Omega)$ & YO $\left(S^{*} \mathbf{s}^{\alpha}\right)$ & $\alpha$ & $C(F)$ & $\mathbf{V T}_{\text {peak }}$ \\
\hline $\mathrm{BP}$ & $0.58 \pm 0.21$ & $6.1 \pm 1.9 \times 10^{3}$ & $3.4 \pm 1.77 \times 10^{-7}$ & $0.58 \pm 0.07$ & $5.01 \pm 0.94 \times 10^{-11}$ & $2.99 \pm 0.37$ \\
\hline $\mathrm{AP}$ & $0.21 \pm 0.05$ & $5.9 \pm 0.6 \times 10^{3}$ & $4.3 \pm 1.9 \times 10^{-7}$ & $0.73 \pm 0.09$ & $5.48 \pm 1.4 \times 10^{-11}$ & $2.74 \pm 0.33$ \\
\hline$p$-value & 0.00017 & 0.77 & 0.14 & $7 \times 10^{-4}$ & 0.24 & 0.002 \\
\hline
\end{tabular}

the CF and PtIr-CF respectively. A paired t-test revealed a statistically significant difference with a $p$-value of $1.62 \times 10^{-6}$.

To determine the $\mathrm{E}_{m c}$ (Cogan, 2008), PtIr-CF were characterized as described in section 2.5.2. In Figure 3 the VT are reported with a Eipp (bias level (Cogan, 2008)) of $0.3 \mathrm{~V}$ and an $\mathrm{E}_{m c}$ ranging from -0.45 to $0.24 \mathrm{~V}$ in the range of the water electrolysis window for PtIr electrodes of -0.6 to $0.8 \mathrm{~V}$ (Rose and Robblee, 1990).

SEM images were collected before and after the coating process. One example of a $\mathrm{CF}$ and a PtIr-CF is reported in Figures 4A,B respectively. The PtIr-CF surface appears homogeneously coated. Detailed SEM of three PtIr-CFs are shown in Figure 4C highlighting a rough, continuous coating. Some surface irregularities are also noted (see yellow arrow of Figure 4C). Adjacent CFs can become temporarily in contact during the plating process, which results in a ridge of PtIr along one side.

EDS was done to evaluate the Pt and Ir percentage of the PtIrCF surface. A percentage of $66 \%$ for Pt and $34 \%$ was measured on one PtIr-CF, consistent with results obtained in a previous set of coated electrodes (Della Valle et al., 2021).

\subsection{Electric Pulsing Tests 3.2.1 $300 \mathrm{~Hz}$ Electric Pulsing Tests}

PtIr-CFs $\left(N=10\right.$, area ranging from 1900 to $\left.2,100 \mu \mathrm{m}^{2}\right)$ were tested by applying biphasic cathodic first electric pulses of $170 \mu \mathrm{s}$ duration at a frequency of $300 \mathrm{~Hz}$ (Chen et al., 2020) with a charge density of $1 \mathrm{mC} / \mathrm{cm}^{2}$ for $12 \mathrm{~h}$ on two consecutive days $(6 \mathrm{~h}$ each day). In Figure $\mathbf{5 A}$ the impedance for one PtIr-CF is reported before (red solid line) and after (blue solid line) 

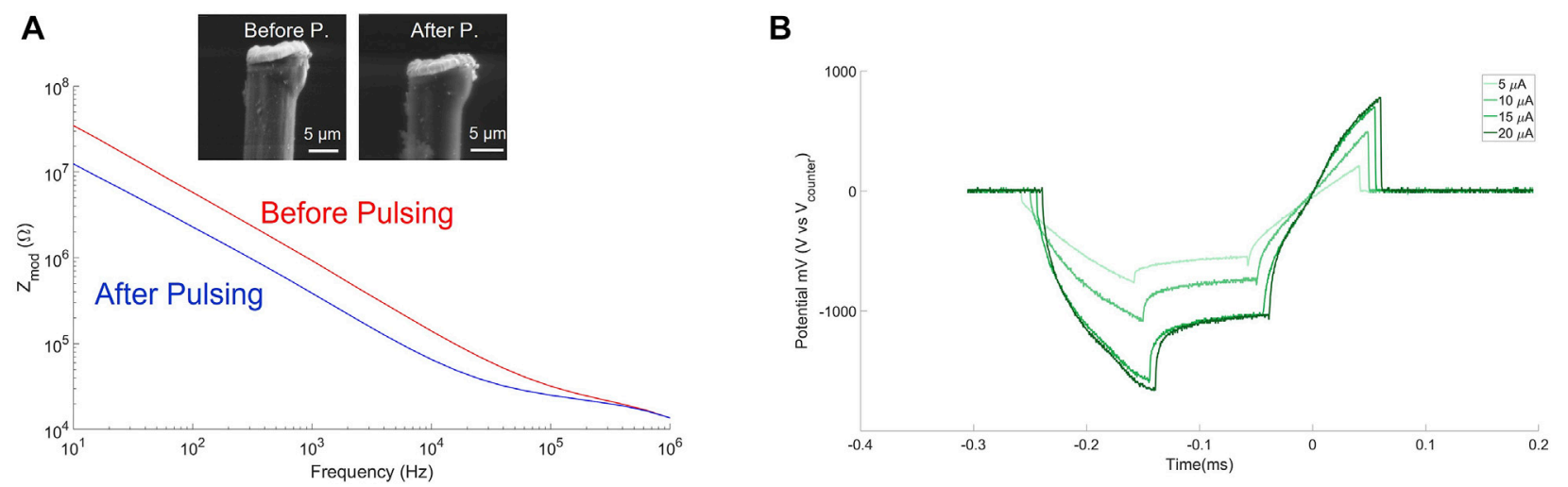

FIGURE 7 | Pulsing test of cellular scale PtIr-CF. (A) Impedance before (red solid line) and after (blue solid line) pulsing for one PtIr-CF; as inset SEM image of the CF before and after pulsing test. (B) Voltage transients when applying a cathodic first biphasic pulse of $100 \mu$ s duration and gap interphase, with current amplitudes from 5 to $20 \mu \mathrm{A}$.

pulsing test on Day 1. An impedance decrease after the pulsing test was obtained for all pulsed PtIr-CFs on both days. Similar decreases in impedance after pulsing have been attributed to the modification of the electrode surface (Fomani and Mansour, 2011; Vomero et al., 2017). In Table 1 the mean, the standard deviation, and the p-value of the normalized impedance at $1 \mathrm{kHz}$ is reported before and after pulsing on both days. The $1 \mathrm{kHz}$ impedance variation before and after pulsing was statistically significant on both Day 1 and Day 2. To further analyze the impedance variation before and after pulsing, a circuit model (see inset in Figure 5A) was fitted and a paired t-test was applied to the extracted parameters. In Table 1 the mean and standard deviation for the extracted parameters is reported with the associated p-value both for Day 1 and Day 2 of pulsing tests. The CPE components values changed, but $\mathrm{Ru}$ was not significantly different before and after pulsing. This further supports the finding that pulsing modified the surface of the electrode (Y0 changed), but did not change the geometric shape (Ru unchanged). No geometric modification was further confirmed by the SEM images shown in Figures 5C-E. $\mathrm{NaCl}$ aggregation was noticed (Figure 5D) on the coated surface and confirmed by EDS (data not shown).

VT were monitored during the pulsing test. One example is shown in Figure 5B, in red and blue are reported VT for Day 1 at the beginning and end of the pulsing tests $(6 \mathrm{~h})$ respectively. In Table 1 the mean and standard deviation of the $\mathrm{VT}_{\text {peak }}$ are reported for Day 1 and Day 2 of pulsing tests. The $p$-values from the paired t-test were statistically significant for both days (Table 1).

\subsection{2 $10 \mathrm{kHz}$ Electric Pulse Tests}

PtIr-CFs $\left(N=10\right.$, area ranging from 1,700 to $\left.2,100 \mu \mathrm{m}^{2}\right)$ were tested at a frequency of $10 \mathrm{kHz}$ (Kapural et al., 2015) by applying biphasic cathodic first electric pulses of $30 \mu$ s duration and a charge density of $1 \mathrm{mC} / \mathrm{cm}^{2}$ for $3 \mathrm{~h}$.

In Figure 6A the EIS of one PtIr-CF before (red solid line) and after (blue solid line) pulsing is reported. As in the $300 \mathrm{~Hz}$ pulsing test, a significant reduction of the $1 \mathrm{kHz}$ impedance was found after pulsing (see Table 2). A circuit model (see inset of Figure $5 \mathbf{A}$ ) was fitted to the impedance data prior to and after pulsing tests. In Table 2 the mean and the standard deviation of the extracted parameters are reported, with a statistically significant difference for the a component of the CPE, which suggests increased capacitive behavior for the electrode surface. The increase in Y0 was not statistically significant.

VT were monitored for the whole pulsing test and the mean of the $\mathrm{VT}_{\text {peak }}$ at the beginning and end of pulsing is reported in Table 2. The $\mathrm{VT}_{\text {peak }}$ variation before and after the pulsing test was statistically significant. SEM inspection showed no surface modifications (Figures 6C-E), an accumulation of salt was detected on the tip of one fiber, as shown in the yellow box in Figure 6D with the corresponding EDS, showing $\mathrm{Na}$ and $\mathrm{Cl}$ molecules in red and yellow as well as in blue and cyan Ir and Pt molecules.

\subsubsection{In vitro Cellular Scale PtIr-CF Pulsing Test}

In vitro pulsing characterization was done using one ZIF with eight small PtIr-CFs (section 2.5.3) to show how electric pulses can be applied using a cellular scale electrode size (less than $15 \mu \mathrm{m}$ diameter, electrode area of $\sim 108 \mu^{2}$ ). In Figure $7 \mathbf{A}$ the impedance before and after pulsing is shown. In Figure $7 \mathbf{B}$ the voltage transients are reported for each current amplitude applied with a max of $784 \mathrm{mV}$ applied across the electrode surface. No structure modifications occurred as confirmed by the SEM (see inset of Figure 7A).

\subsection{In vivo Electric Pulsing Test}

One HDCF board with one coated CF (PtIr-HDCF, area-2000 $\mu^{2}$ ) was used to perform pilot tests of in vivo electric pulsing test in rat visual cortex. As explained in the method section 2.6.3, VT were first collected at $300 \mu \mathrm{m}$ depth at four different current amplitudes as shown in Figure 8A.

Then the PtIr-HDCF was driven at $600 \mu \mathrm{m}$ of depth into the visual cortex. The tissue was stimulated for a total of $1 \mathrm{~h}$ at $25 \mu \mathrm{A}$ $\left(0.3 \mathrm{mC} / \mathrm{cm}^{2}\right)$ and $5 \mu$ s interphase gap. VTs were collected each 10 min as shown in Figure 8B. The mean of the $\mathrm{VT}_{\text {peak }}$ was of 


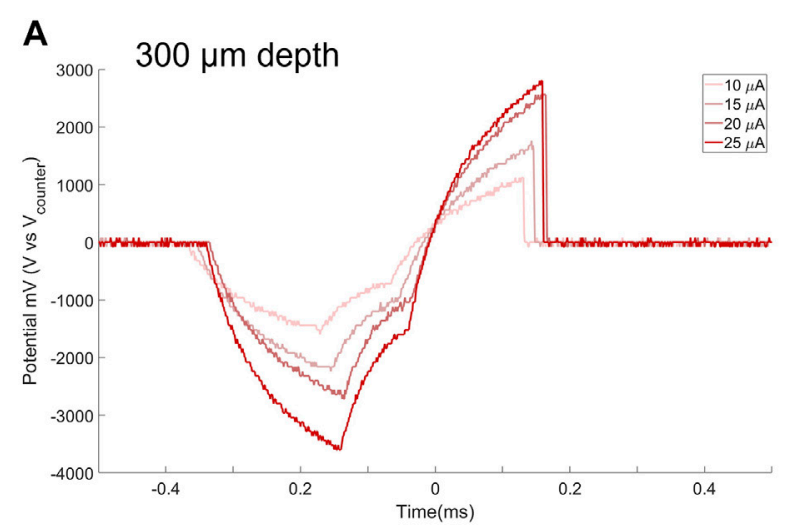

C

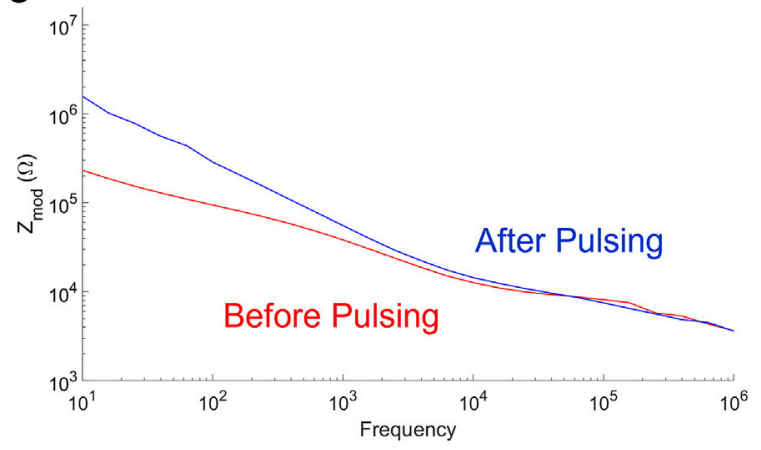

B $\quad 600 \mu \mathrm{m}$ depth

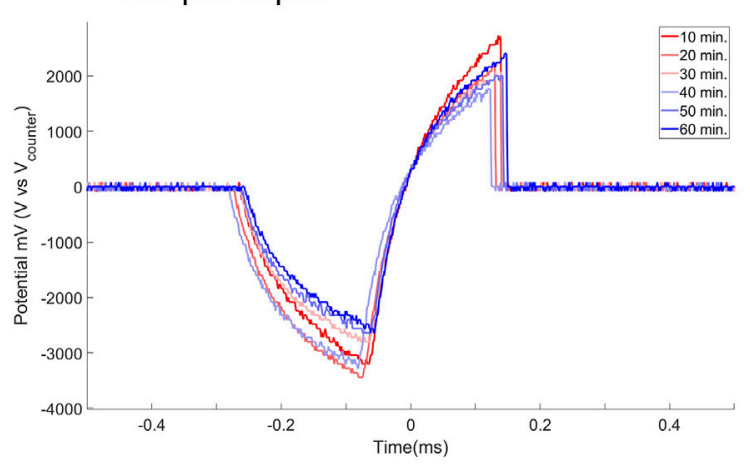

D

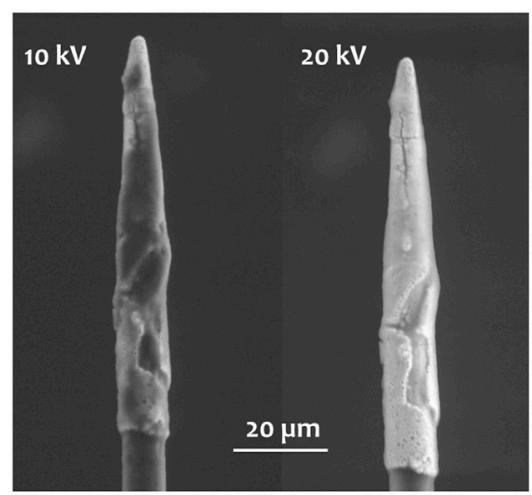

FIGURE 8 | In vivo pulsing tests. (A) VT recorded in rat visual cortex at depth of $300 \mu \mathrm{m}, 6,000$ cathodic first biphasic pulses of $200 \mu \mathrm{s}$ duration, $100 \mu \mathrm{s}$ gap interphase at $50 \mathrm{~Hz}$ were delivered at four different current amplitudes (10, 15, 20 and $25 \mu \mathrm{A})$. (B) VT in vivo pulsing test (1 h) at $600 \mu \mathrm{m}$ depth recorded every 10 min (C) PtIr-HDCF impedance before (red solid line) and after (blue solid line) the in vivo pulsing test. (D) SEM of the PtIr-HDCF after the in vivo pulsing test acquired at $10 \mathrm{kV}$ (left) and $20 \mathrm{kV}$ (right).

$2.19 \pm 0.3 \mathrm{~V}$ and a lower VT was recorded at the end of the pulsing test.

In Figure 8C the PtIr-HDCF impedance before (red solid line) and after (blue solid line) the in vivo pulsing test are reported. After the in vivo pulsing test, the impedance magnitude of the PtIrHDCF was slightly increased possibly due to biological tissue adhering on the electrode surface.

SEM were acquired after the in vivo pulsing test. In Figure 8D, left panel the SEM at $10 \mathrm{kV}$ is reported showing in black, low conductive material adhering on the surface (e.g., biological material). On the right panel of Figure 8D the SEM at $20 \mathrm{kV}$ is reported and the PtIr is visible with a crack in the PtIr film near the tip. No SEM was acquired prior to stimulation, so it is unclear when the crack formed. Since the VTs during the in vivo experiments were stable, it is more likely that the crack was due to a defect during PtIr deposition or as a result of handling during insertion or SEM preparation.

\section{DISCUSSION}

The development of small microelectrodes for localized neural stimulation is the key challenge facing neural interfaces. CFEA have proven to effectively provide neural recording from the motor cortex (Patel et al., 2015, 2016; Massey et al., 2019) as well as from the peripheral nerve (Gillis et al., 2018; Dehdashtian et al., 2020; Welle et al., 2021). We recently (Della Valle et al., 2021) demonstrated how electroplated PtIr can decrease CF impedance with a good coating adherence. However, the stability of PtIr-CFs under electric pulsing test has not been investigated. In the studies presented here, we found PtIr-CFs can inject $1.25 \mathrm{mC} / \mathrm{cm}^{2}(0.5 \mathrm{~ms}$ pulses in PBS) while staying within the water window for PtIr. The corresponding current amplitude of $40 \mu \mathrm{A}$ was well above published activation thresholds for cortical microstimulation (Schmidt et al., 1996). Pulse testing at $300 \mathrm{~Hz}$ and $10 \mathrm{kHz}$ resulted in decreases in impedance and voltage transients, consistent with other studies of chronic stimulation (Fomani and Mansour, 2011). This phenomenon does not indicate electrode instability, rather a modification of the surface or cleaning of the exposed electrode area (Fomani and Mansour, 2011; Vomero et al., 2017). Two pilot experiments demonstrated stimulation, with a cellular scale electrode in vitro and a sharpened CF in the visual cortex, which also suggests relatively stable electrochemical properties. In all stimulation experiments, visual inspection with SEM found no coating loss or delamination. In general, PtIr-CF appears to be stable for the conditions tested. Our 
findings are comparable to other recent work on ultra microelectrodes and materials for microstimulation. Deku et al. (2018) recently developed ultrasmall silicon carbide electrodes (electrode site area from 20 to $200 \mu \mathrm{m}^{2}$ ) coated either with titanium nitrite (TiN) and sputtered iridium oxide films (SIROF) that provided more than $1 \mathrm{nC} / \mathrm{ph}$ of charge injection within water electrolysis limits with a $200 \mu$ s pulse. Boehler et al. (Boehler et al., 2020) presented nano-structured platinum (nano- $\mathrm{Pt}$ ) coatings that were able to provide low impedance microelectrodes $(\varnothing 35 \mu \mathrm{m})$ with good electric stability in response to pulsing test both in vitro (1.5 billion pulses of $1.5 \mathrm{mC} / \mathrm{cm}^{2}$ ) and in vivo over 5 weeks of implantation for recording and stimulation of mice medial septal nucleus using a $125 \mu \mathrm{m}$ nano-Pt coated wire. Zheng et al. (2017), characterized $200 \mu \mathrm{m}$ IrOx nano-Pt microelectrodes in vitro as potential stimulating microelectrodes providing a charge density of $1.2 \mathrm{mC} / \mathrm{cm}^{2}$.

Finally, voltage transient data measured in vivo includes the voltage across both the PtIr-CF electrode and the return electrode. Thus, we did not measure electrode polarization across PtIr-CF in vivo. However, it is known that electrode polarization is generally greater in vivo (Leung et al., 2014) or in model cerebrospinal fluid (Cogan et al., 2007), versus PBS solution, which we used for electrode polarization measurements (Figure 3). Our VT data showing higher voltage in vivo is consistent with these earlier studies. For the same current and pulse width, we found VTs to be two to three times greater in vivo vs. in vitro. The VT waveforms in vivo tend to be rounded, making accurate estimates of polarization difficult. Leung et al. (Leung et al., 2014), determined charge injection limits in vivo for retinal, cochlear, and subdural locations, using the same methods for determining charge injection limits in vitro. The in vivo charge injection limits they found were well below charge density limits found by postmortem tissue assessment. The authors concluded that in vivo charge injection limits cannot be measured in the same manner as in vitro tests. EIS taken before and after in vivo pulse testing suggested no coating loss on the electrode surface, which was confirmed by SEM. We noted a crack in the coating after in vivo stimulation, but this PtIr-CF had no SEM performed prior to pulse testing. Our in vivo experiments should be considered preliminary and the next experiments will be augmented with chronic implantation and stimulation, tissue analysis, and imaging data pre and post test implant to determine the safety of stimulation with PtIr-CFs.

\section{REFERENCES}

A. Fomani, A., and Mansour, R. R. (2011). Fabrication and Characterization of the Flexible Neural Microprobes with Improved Structural Design. Sensors Actuators A: Phys. 168, 233-241. doi:10.1016/j.sna.2011.04.024

Ali, M. A., Hu, C., Jahan, S., Yuan, B., Saleh, M. S., Ju, E., et al. (2021). Sensing of COVID-19 Antibodies in Seconds via Aerosol Jet Nanoprinted ReducedGraphene-Oxide-Coated 3D Electrodes. Adv. Mater. 33, 2006647. doi:10.1002/adma.202006647

Beebe, X., and Rose, T. L. (1988). Charge Injection Limits of Activated Iridium Oxide Electrodes with 0.2 Ms Pulses in Bicarbonate Buffered saline

\section{DATA AVAILABILITY STATEMENT}

The raw data supporting the conclusion of this article will be made available by the authors, without undue reservation.

\section{ETHICS STATEMENT}

The animal study was reviewed and approved by the Michigan State University Institutional Animal Care and Use Committee (IACUC).

\section{AUTHOR CONTRIBUTIONS}

JW contributed to the conception of the study. EDV and JW contributed to the design of the study. EDV performed in vitro experiments and data curation. PRP fabricated CF and HDCF arrays. BK and QW performed in vivo experiments. All authors contributed to manuscript revision, read, and approved the submitted version.

\section{FUNDING}

This work was financially supported by the National Science Foundation (DMR-1625671, NSF award CBET 2129817), by the National Institutes of Health National Institute of Neurological Disorders and Stroke (UF1NS107659), the Office of the Director National Institutes of Health (OT2OD024907), the NSF-funded NeuroNex MINT hub (Multimodal Integrated Neural Technologies) at the University of Michigan under NSF 1707316, the Kellogg Vision Research Core funded by P30 EY007003 from the National Eye Institute, The University of Michigan College of Engineering, the School of Medicine, and Research to Prevent Blindness.

\section{ACKNOWLEDGMENTS}

The authors acknowledge the Michigan Center for Materials Characterization and the Lurie Nanofabrication Facility for use of their instruments and staff assistance. The authors acknowledge technical support from Julianna Richie from the Cortical Neural Prosthetics Lab at University of Michigan.

(Neurological Stimulation Application). IEEE Trans. Biomed. Eng. 35, 494-495. doi:10.1109/10.2122

Boehler, C., Vieira, D. M., Egert, U., and Asplund, M. (2020). NanoPt-A Nanostructured Electrode Coating for Neural Recording and Microstimulation. ACS Appl. Mater. Inter. 12, 14855-14865. doi:10.1021/acsami.9b22798

Cassar, I. R., Yu, C., Sambangi, J., Lee, C. D., Whalen, J. J., III, Petrossians, A., et al. (2019). Electrodeposited Platinum-Iridium Coating Improves In Vivo Recording Performance of Chronically Implanted Microelectrode Arrays. Biomaterials 205, 120-132. doi:10.1016/j.biomaterials.2019.03.017

Chen, X., Wang, F., Fernandez, E., and Roelfsema, P. R. (2020). Shape Perception via a High-Channel-Count Neuroprosthesis in Monkey Visual Cortex. Science 370, 1191-1196. doi:10.1126/science.abd7435 
Cogan, S. F., Ludwig, K. A., Welle, C. G., and Takmakov, P. (2016). Tissue Damage Thresholds during Therapeutic Electrical Stimulation. J. Neural Eng. 13, 021001. doi:10.1088/1741-2560/13/2/021001

Cogan, S. F. (2008). Neural Stimulation and Recording Electrodes. Annu. Rev. Biomed. Eng. 10, 275-309. doi:10.1146/annurev.bioeng.10.061807.160518

Cogan, S., Peramunage, D., Smirnov, A., Ehrlich, J., Mccreery, D., and Manoonkitiwongsa, P. (2007). Polyethylenedioxythiophene (Pedot) Coatings for Neural Stimulation and Recording Electrodes. Mater. Res. Soc. Meet. Abstr. QQ2. 7.

Dalrymple, A. N., Huynh, M., Robles, U. A., Marroquin, J. B., Lee, C. D., Petrossians, A., et al. (2019). Electrochemical and Mechanical Performance of Reduced Graphene Oxide, Conductive Hydrogel, and Electrodeposited Pt-Ir Coated Electrodes: an Activein Vitrostudy. J. Neural Eng. 17, 016015. doi:10.1088/1741-2552/ab5163

Dehdashtian, A., Ursu, D., Patel, P. G., Welle, E., Chestek, C. A., Cederna, P. S., et al. (2020). Abstract 193. Plast. Reconstr. Surg. - Glob. Open 8, 131-132. doi:10.1097/01.gox.0000667828.04397.6c

Deku, F., Cohen, Y., Joshi-Imre, A., Kanneganti, A., Gardner, T. J., and Cogan, S. F. (2018). Amorphous Silicon Carbide Ultramicroelectrode Arrays for Neural Stimulation and Recording. J. Neural Eng. 15, 016007. doi:10.1088/1741-2552/aa8f8b

Della Valle, E., Welle, E. J., Chestek, C. A., and Weiland, J. D. (2021). Compositional and Morphological Properties of Platinum-Iridium Electrodeposited on Carbon Fiber Microelectrodes. J. Neural Eng. 8 (5). doi:10.1088/1741-2552/ac20bb

Dupont, S. R., Novoa, F., Voroshazi, E., and Dauskardt, R. H. (2014). Decohesion Kinetics of PEDOT:PSS Conducting Polymer Films. Adv. Funct. Mater. 24, 1325-1332. doi:10.1002/adfm.201302174

Fan, B., Rodriguez, A. V., Vercosa, D. G., Kemere, C., and Robinson, J. T. (2020). Sputtered Porous Pt for Wafer-Scale Manufacture of Low-Impedance Flexible Microelectrodes. J. Neural Eng. 17, 036029. doi:10.1088/1741-2552/ab965c

Gillis, W. F., Lissandrello, C. A., Shen, J., Pearre, B. W., Mertiri, A., Deku, F., et al. (2018). Carbon Fiber on Polyimide Ultra-microelectrodes. J. Neural Eng. 15, 016010. doi:10.1088/1741-2552/aa8c88

Goldberg, I. B., Bard, A. J., and Feldberg, S. W. (1972). Resistive Effects in Thin Electrochemical Cells. Digital Simulations of Electrochemistry in Electron Spin Resonance Cells. J. Phys. Chem. 76, 2550-2559. doi:10.1021/j100662a013

Huan, Y., Gill, J. P., Fritzinger, J. B., Patel, P. R., Richie, J. M., della Valle, E., et al. (2021). Carbon Fiber Electrodes for Intracellular Recording and Stimulation. bioRxiv.

Jiman, A. A., Ratze, D. C., Welle, E. J., Patel, P. R., Richie, J. M., Bottorff, E. C., et al. (2020). Multi-channel Intraneural Vagus Nerve Recordings with a Novel HighDensity Carbon Fiber Microelectrode Array. BioRxiv 10 (1). doi:10.1038/ s41598-020-72512-7

Kapural, L., Yu, C., Doust, M. W., Gliner, B. E., Vallejo, R., Sitzman, B. T., et al. (2015). Novel 10-kHz High-Frequency Therapy (HF10 Therapy) Is Superior to Traditional Low-Frequency Spinal Cord Stimulation for the Treatment of Chronic Back and Leg Pain. Anesthesiology 123, 851-860. doi:10.1097/ aln.0000000000000774

Klein, J. D., Clauson, S. L., and Cogan, S. F. (1989). Morphology and Charge Capacity of Sputtered Iridium Oxide Films. J. Vacuum Sci. Tech. A: Vacuum, Surf. Films 7, 3043-3047. doi:10.1116/1.576313

Kollo, M., Racz, R., Hanna, M.-E., Obaid, A., Angle, M. R., Wray, W., et al. (2020). Chime: Cmos-Hosted In Vivo Microelectrodes for Massively Scalable Neuronal Recordings. Front. Neurosci. 14, 834. doi:10.3389/fnins.2020.00834

Kozai, T. D. Y., Langhals, N. B., Patel, P. R., Deng, X., Zhang, H., Smith, K. L., et al. (2012). Ultrasmall Implantable Composite Microelectrodes with Bioactive Surfaces for Chronic Neural Interfaces. Nat. Mater 11, 1065-1073. doi:10.1038/nmat3468

Lee, C. D., Hudak, E. M., Whalen, J. J., III, Petrossians, A., and Weiland, J. D. (2018). Low-impedance, High Surface Area Pt-Ir Electrodeposited on Cochlear Implant Electrodes. J. Electrochem. Soc. 165, G3015-G3017. doi:10.1149/2.0031812jes

Leung, R. T., Shivdasani, M. N., Nayagam, D. A., and Shepherd, R. K. (2014). In Vivo and In Vitro Comparison of the Charge Injection Capacity of Platinum Macroelectrodes. IEEE Trans. Biomed. Eng. 62, 849-857. doi:10.1109/ TBME.2014.2366514

Massey, T. L., Santacruz, S. R., Hou, J. F., Pister, K. S. J., Carmena, J. M., and Maharbiz, M. M. (2019). A High-Density Carbon Fiber Neural Recording Array Technology. J. Neural Eng. 16, 016024. doi:10.1088/1741-2552/aae8d9

Norlin, A., Pan, J., and Leygraf, C. (2004). Investigation of Electrochemical Behavior of Stimulation/sensing Materials for Pacemaker Electrode Applications: I. Pt, Ti, and Tin Coated Electrodes. J. Electrochem. Soc. 152, J7. doi:10.1149/1.1842092
Patel, P. R., Na, K., Zhang, H., Kozai, T. D. Y., Kotov, N. A., Yoon, E., et al. (2015). Insertion of Linear 8.4 $\mu \mathrm{m}$ Diameter 16 Channel Carbon Fiber Electrode Arrays for Single Unit Recordings. J. Neural Eng. 12, 046009. doi:10.1088/1741-2560/ 12/4/046009

Patel, P. R., Zhang, H., Robbins, M. T., Nofar, J. B., Marshall, S. P., Kobylarek, M. J., et al. (2016). Chronicin Vivostability Assessment of Carbon Fiber Microelectrode Arrays. J. Neural Eng. 13, 066002. doi:10.1088/1741-2560/13/ $6 / 066002$

Polikov, V. S., Tresco, P. A., and Reichert, W. M. (2005). Response of Brain Tissue to Chronically Implanted Neural Electrodes. J. Neurosci. Methods 148, 1-18. doi:10.1016/j.jneumeth.2005.08.015

Posey, F. A., and Morozumi, T. (1966). Theory of Potentiostatic and Galvanostatic Charging of the Double Layer in Porous Electrodes. J. Electrochem. Soc. 113, 176. doi:10.1149/1.2423897

Rose, T. L., and Robblee, L. S. (1990). Electrical Stimulation with Pt Electrodes. Viii. Electrochemically Safe Charge Injection Limits with $0.2 \mathrm{Ms}$ Pulses (Neuronal Application). IEEE Trans. Biomed. Eng. 37, 1118-1120. doi:10.1109/10.61038

Schmidt, E. M., Bak, M. J., Hambrecht, F. T., Kufta, C. V., O’Rourke, D. K., and Vallabhanath, P. (1996). Feasibility of a Visual Prosthesis for the Blind Based on Intracortical Micro Stimulation of the Visual Cortex. Brain 119, 507-522. doi:10.1093/brain/119.2.507

Vomero, M., Castagnola, E., Ciarpella, F., Maggiolini, E., Goshi, N., Zucchini, E., et al. (2017). Highly Stable Glassy Carbon Interfaces for Long-Term Neural Stimulation and Low-Noise Recording of Brain Activity. Sci. Rep. 7, 1-14. doi:10.1038/srep40332

Wang, Y., Graham, S., and Unsworth, C. P. (2021). Superior Galvanostatic Electrochemical Deposition of Platinum Nanograss Provides High Performance Planar Microelectrodes for In Vitro Neural Recording. J. Neural Eng. doi:10.1088/1741-2552/ac1bc1

Welle, E. J., Patel, P. R., Woods, J. E., Petrossians, A., Della Valle, E., Vega-Medina, A., et al. (2020). Ultra-small Carbon Fiber Electrode Recording Site Optimization and Improved In Vivo Chronic Recording Yield. J. Neural Eng. 17, 026037. doi:10.1088/1741-2552/ab8343

Welle, E. J., Woods, J. E., Jiman, A. A., Richie, J. M., Bottorff, E. C., Ouyang, Z., et al. (2021). Sharpened and Mechanically Durable Carbon Fiber Electrode Arrays for Neural Recording. IEEE Trans. Neural Syst. Rehabil. Eng. 29, 993-1003. doi:10.1109/tnsre.2021.3082056

Xie, C., Liu, J., Fu, T.-M., Dai, X., Zhou, W., and Lieber, C. M. (2015). Threedimensional Macroporous Nanoelectronic Networks as Minimally Invasive Brain Probes. Nat. Mater 14, 1286-1292. doi:10.1038/nmat4427

Zeng, Q., Xia, K., Sun, B., Yin, Y., Wu, T., and Humayun, M. S. (2017). Electrodeposited Iridium Oxide on Platinum Nanocones for Improving Neural Stimulation Microelectrodes. Electrochimica Acta 237, 152-159. doi:10.1016/j.electacta.2017.03.213

Zhou, D. M. (2005). Platinum Electrode and Method for Manufacturing the Same. US Patent 6 (974), 533, 2005 . [Dataset].

Zhou, D. M. (2011). Platinum Electrode Surface Coating and Method for Manufacturing the Same. US Patent 7 (887), 681, 2011 . [Dataset].

Conflict of Interest: The author JW has a financial interest in PtIr coating.

The remaining authors declare that the research was conducted in the absence of any commercial or financial relationships that could be construed as a potential conflict of interest.

Publisher's Note: All claims expressed in this article are solely those of the authors and do not necessarily represent those of their affiliated organizations, or those of the publisher, the editors, and the reviewers. Any product that may be evaluated in this article, or claim that may be made by its manufacturer, is not guaranteed or endorsed by the publisher.

Copyright (C) 2021 della Valle, Koo, Patel, Whitsitt, Purcell, Chestek and Weiland. This is an open-access article distributed under the terms of the Creative Commons Attribution License (CC BY). The use, distribution or reproduction in other forums is permitted, provided the original author(s) and the copyright owner(s) are credited and that the original publication in this journal is cited, in accordance with accepted academic practice. No use, distribution or reproduction is permitted which does not comply with these terms. 